\title{
Exploring the Success Factors of Hybrid Micro-Enterprises
}

\author{
Marta Bicho, Ralitza Nikolaeva, Carmen Lages, and Fernando A.F. Ferreira
}

\begin{abstract}
This research explores hybrid micro-entrepreneurs' founding motivations and the transformation of those motivations into visions of success, by applying multiple criteria decision analysis (MCDA). We find that entrepreneurs of hybrid micro-enterprises are driven mostly by noneconomic goals and that those influence their vision of success. The success framework consists of seven indicators (training, professional development, marketing, management, external factors, infrastructures, and organizational aspects). Human capital is perceived as the most important for success - translating the professional motivations for founding. Reversely, external factors, which are usually considered crucial to attain legitimacy, are perceived the least important factors. Given the findings, are hybrid micro-entrepreneurs ready to succeed?
\end{abstract}

Keywords Hybrid micro-enterprise - Success factors - Cognitive mapping • Multiple criteria decision analysis

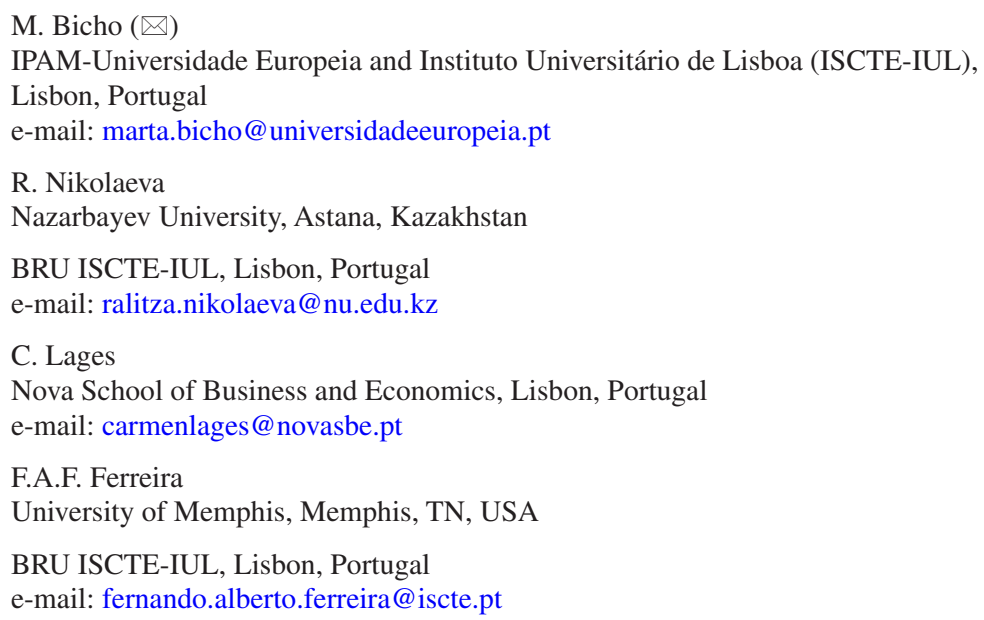




\section{Introduction}

The study of entrepreneurship is contentious, and adding any prefixes does not make researchers' task easier (Zahra et al. 2009). Thus, inserting the prefix "micro" creates one layer of extra definitional issues. Adding "hybrid" in the mix is starting to sound as a hangover recipe. Before rushing to a definitional quagmire of two prefixes, we want to lay out certain regularities and questions documented by prior research. As noted by Zahra et al. (2009), entrepreneurs often have diverse motivations for starting an enterprise, and commercial entrepreneurs are usually driven and measured by profit. What about noncommercial entrepreneurs? The same authors present a table of numerous definitions of social enterprises whose common theme is that they have both economic and social objectives. Further, social enterprising often crosses over and spans different market categories which raises legitimacy questions (Ruebottom 2013).

Researchers suggest that social enterprises are prime examples of hybrid organizations as they have multiple goals and combine different institutional logics (Battilana and Lee 2014; Battilana et al. 2015; Doherty et al. 2014). "Hybrids face the distinct challenge of trying to optimize performance on multiple dimensions as they pursue multiple objectives at once" (Battilana et al. 2015, p. 1680). The combination of multiple organizational forms depart from regular, socially, and legitimate organizational templates, and thus hybrid organizations often experience unique organizing challenges, such as legitimacy vacuum (Battilana and Lee 2014; Dobrev and Gotsopoulos 2010; Ruebottom 2013). Thus, the big question that we see arising for entrepreneurs of hybrid organizations is the reconciliation of multiple and often conflicting objectives. We want to know what entrepreneurs of hybrid organizations mean by success from the very conception of the organization. As such we are interested in how they define their objectives and assess their performance. In particular, to what extent economic goals are reconciled with social impact goals in hybrid entrepreneurs' vision of success. Thus, we respond to Battilana and Lee's (2014) call for construction of hybrid performance measures as one of the most prominent challenges to researchers in the field.

The goal of the current study is to explore the motivations of entrepreneurs for starting hybrid organizations and to what extent these motivations shape their vision of success. This goal builds on Zahra et al.'s (2009) articulation of the need to appreciate the motivations of individuals who plunge into creating new types of organizations.

The presence of multiple goals and how entrepreneurs manage and balance multiplicity with the requirements of the organizational goals shape their vision of the success (Battilana and Lee 2014). Previous studies show that there is no consensus about the appropriate set of indicators to adequately assess the success of enterprises (Combs et al. 2005; Murphy et al. 1996). Adding "micro" and "hybrid" prefixes to enterprises makes the picture more complex. For instance, it seems that hybrid enterprises experience unique external and internal tensions due to multiple tensions that they need to respond to (Battilana and Lee 2014). Thus, it may be 
particularly challenging for hybrid micro-enterprises to assess the fit at two levels (between internal capabilities and external market conditions) and yet be consistent with their dual purpose (Battilana and Lee 2014; Reijonen and Komppula 2007; Simpson et al. 2012). For example, a social entrepreneur might have a good solution to a local social problem but might fail on the financial sustainability of the enterprise. Second, the higher complexity of assessing the dual fit is exacerbated by the extremely limited pool of resources available to a micro-enterprise. Thus, coming up with a set of key success indicators leading to survival and continuity can be daunting for hybrid micro-enterprises.

We contend that it is important to investigate the construction of success indicators for micro-enterprises as they play a crucial role in the ultimate survival of the enterprises. While researchers and entrepreneurs quickly point to lack of resources as a leading cause of the high failure rates of micro-enterprises, unclear vision of success may be a more fundamental reason. This is a complex proposition that would take more than one research study to explore and confirm. With the current one, we take the initial step. We know that entrepreneurs start ventures for a host of reasons and they do not need to be motivated by wealth attainment in order to be successful (Amit et al. 2001). The question, though, is how to know if the various motives can lead to success.

This study intends to answer to the research question: "what are the motivations of entrepreneurs for starting hybrid organizations and to what extent these motivations shape their vision of success?" In order to answer this question, we take stock of hybrid micro-entrepreneurs' founding motivations and perceived success factors. For the purpose, we employ two different types of approaches in two different samples of micro-entrepreneurs within the same hybrid category. First, we use in-depth interviews to explore the motivations driving the creations of the ventures. Then, with a different sample, we apply cognitive mapping and multiple criteria decision making analysis (MCDA) to assist the entrepreneurs in creating an evaluation framework of key success indicators. The decision to employ cognitive mapping and MCDA is driven by the complex, dual-identity nature of a hybrid organization. The combined use of these constructivist tools helps decision-makers to think and discuss the problem at hand and guide them in identifying the best options (Belton and Stewart 2002; Ferreira et al. 2010). Thus, we can see how initial motivations from the entrepreneur's perspective get transformed by a group consensus to key success factors. We find that individual motivations seem to be driven by noneconomic factors - whether because the founders had very satisfactory personal experience in the area and they want to disseminate the benefits or they identified a growing number of customers seeking those benefits or the dissatisfaction of founders with their prior professional activity. These factors seem to be reflected in the resulting MCDA framework of success comprising of seven fundamental points of view (FPVs), among which the three most important are professional development, training, and management.

This study contributes to the literature by building a first of its kind evaluation framework to assess hybrid micro-enterprises success. It responds to recent calls for research in understanding how micro-enterprises and hybrid organizations sustain 
their business (Battilana and Lee 2014; Rauch et al. 2009). The success factors of hybrid micro-enterprises may differ compared to traditional enterprises, because of the legitimacy vacuum context in which they may operate. Therefore, hybrid microenterprises need to build their own business logic, which in turn might influence the way they evaluate factors affecting their success. Inadvertently, the founding motivations would find place in notions of success, which is why Battilana and Lee (2014) call for future research to investigate not only the influence of performance measures on a hybrid organization's sustainability but also the influence of the founder on performance incentives and management. Therefore, we contribute to the creation of a systematic set of criteria that entrepreneurs identified as success drivers. We achieve this by applying creating a multidimensional framework, which integrates cognitive mapping and the measurement attractiveness by a categoricalbased evaluation technique (MACBETH) (an MCDA method). The combined use of these techniques resulted in the added contribution of community reach-out through the practical application of the success framework. The participants in the study - micro-entrepreneurs with limited resources - received evaluations of their enterprises based on the constructed framework for success, which they considered very helpful.

\section{Hybrid Micro-Enterprises and Success}

For the purpose of our study, micro-enterprises are "very small enterprises in scale, scope or capability" (Markman and Waldron 2014, p. 180). There are a number of ways by which micro-enterprises have been defined, such as small structure (e.g., less than ten employees), the volume of sales, management centralization, and structural lack of resources (Courrent and Gundolf 2008). Previous research has also emphasized that micro-enterprises focus on a particular market niche, especially in markets dominated by large incumbents, where micro-enterprises can either complement their offers or target small niches unattractive to their counterparts (Markman and Waldron 2014). Micro-enterprises represent a major part of the European business establishments; however research in micro-enterprises has been scarce (Courrent and Gundolf 2008). It has been noted that very little theoretical progress has been made concerning the success factors of micro-enterprises (Simpson et al. 2012). Despite that, it has been observed that the success rates of micro-enterprises are very low and are subject to a variety of barriers, such as resource constraints, vulnerability, uncertainty, risk, market inexperience, and lack of legitimacy (Reijonen and Komppula 2007; Courrent and Gundolf 2008; Short et al. 2009; Markman and Waldron 2014).

When micro-enterprises are of a hybrid nature, the question of success becomes even more complex. For the purposes of this study, hybrid organizations both "pursue a social mission and sustain their operations through commercial activities" (Battilana et al. 2015, p. 1658). Hybridity is a matter of degree, in a continuum where at one extreme social and commercial aspects are differentiated and at another 
extreme are integrated, and, as such, hybrid organizations vary in the "level of integration between the social and commercial aspects" (Battilana and Lee 2014, p. 426). In order to study how hybrid organizations integrate both aspects, Battilana and Lee (2014, p. 403) focused on and defined hybrid organizing as "the activities, structures, processes, and meanings by which organizations make sense of and combine aspects of multiple organizational forms." The authors suggested five dimensions of hybrid organizing: core organizational activities (commercial and social activities), workforce composition (most workforce is socialized either in the social or the commercial section and is not hybrid), organizational design (how leaders translate strategy into action including formal organizational structure, incentives, control systems, and governance), culture (organizational shared values and norms of behavior), and interorganizational relationships (network of relationship with investors or partners). As noted by Moss et al. (2011), the success of social enterprises - as examples of hybrid organizations with dual identities - is gauged not only by their financial success but also by their social mission and impact. When an enterprise has multiple identities/goals, it may be difficult to reconcile them, and such a lack of consensus may lead to a blurred vision of success (Battilana and Lee 2014). However, Zahra et al. (2009) observe that all of the numerous definitions of enterprises with mixed motives are silent on how to assess the success of such ventures. Moreover, hybrid organizations face higher skepticism from various stakeholders due to their dual identity and category crossover. Under such legitimacy-deficient conditions, stakeholders are more reluctant to support the enterprises because of the lack of institutional consent and difficulty in assessing the firm's potential for success (Dobrev and Gotsopoulos 2010; van Werven et al. 2015). A hybrid organization is characterized by conflicting institutional demands (Santos and Eisenhardt 2005), which limit its potential for success. Thus, a hybrid nature adds an extra layer of obstacles to micro-enterprises that already experience high business failure rates (Jones et al. 2014). Given such unfavorable odds, the aim of this study is to dissect the terms in which managers of hybrid micro-enterprises define success. One could ask if high failure rates are not only primarily due to resource constraints but also due to lack of clear vision of success.

\section{Context}

The context of our study is the complementary and alternative medicine (CAM) micro-enterprise. CAM includes alternative or unorthodox therapies such as (a) alternative medical systems (e.g., acupuncture, naturopathy, homeopathy), (b) mind-body interventions (e.g., biofeedback, hypnosis), (c) biologically based treatments (e.g., aromatherapy, iridology), (d) manipulative and body-based methods (reflexology, massage, osteopathy), and (e) energy therapies (reiki, healing) (Frass et al. 2012). CAM services include therapies based in holistic and whole person philosophy, empowerment of the patient, and use of natural remedies. Microenterprises offering CAM services are a good example of hybrid enterprises 
encountering legitimacy obstacles as many such therapies are contested. Thus, CAM enterprises exist in a healthcare market category with unclear boundaries, and healthcare is one of the original industries where hybrid organizations have been studied (Battilana and Lee 2014; Ruef and Scott 1998).

\section{Methodology}

For the first study, we employed a qualitative technique to better understand the founding motivations of the entrepreneurs of hybrid micro-enterprises. We interviewed 11 founders/managers of hybrid micro-enterprises, with each semistructured interview lasting between 40 and $105 \mathrm{~min}$. The interviews were recorded and transcribed, and two of the authors examined the transcripts independently going through iterative rounds until they reached a consensus on the interpretation. For the second study, we apply cognitive mapping and MCDA to assist the entrepreneurs in creating an evaluation framework of key success indicators. These two methodological approaches are well established in the decision science arena and thus have the potential to be applied to other fields where decision-making is essential (Ferreira et al. 2015). Their combined use allow us to map a vast number of factors identified by a group of seven entrepreneurs and, simultaneously, incorporate a learning process and discussion until a consensus is reached (Ferreira et al. 2015). The process is interactive, which allows entrepreneurs to discuss and structure the conception of the evaluation framework in an open environment. Specifically, we propose a multidimensional framework that integrates cognitive mapping and the measurement attractiveness by a categorical-based evaluation technique (MACBETH) (Bana e Costa et al. 2012). Cognitive maps help decision-makers to structure the problem as they identify the key criteria to assess success of microenterprises. They are especially helpful as they facilitate the entrepreneurs' decision in a complex context, such as the one of a hybrid organization. The MACBETH method enables the estimation of trade-offs among criteria, which in turn supports the development of the final evaluation framework (Ferreira et al. 2010).

\section{Discussion}

This research aims at studying how hybrid micro-enterprises conceptualize success beyond the founding impetus. Our focus is on the complementary and alternative medicine (CAM) context. Beyond the regular hurdles of micro-enterprises (e.g., resource constraints, vulnerability, uncertainty, risk, etc.) (Markman and Waldron 2014), the hybrid nature of the organizations of this study and the contested category they operate in brings additional complexity because the micro-enterprises face a non-supportive environment that limits the chances of firm's success and survival. 
Many entrepreneurs start with more idealistic and optimistic ideas of their ventures (Cooper et al. 1994), and they become disappointed when reality hits (Hmieleski and Baron 2009). Consequently, can we expect that the social logic becomes more balanced with the economic logic of success after the hybrid enterprise has been in business for some time? To answer this question, we invited managers of CAM micro-enterprises to develop an evaluation framework to assess factors affecting enterprise success. We obtained seven indicators - training, professional development, marketing, management, external factors, infrastructures, and organizational aspects. The indicators professional development and training are the most important and represent $45.46 \%$ of the overall success framework. Marketing, management, and organizational aspects factors correspond to $48.27 \%$. Representing only $7.07 \%$ of the overall success are the indicators infrastructures $(6.06 \%)$ and external factors (beyond managers' control) (1.01\%).

Based on these findings, we can highlight that the main motivations of entrepreneurs to found a CAM enterprise, mostly related with collective well-being, are confirmed by the most important factors identified as success factors - training and professional development. We can thus conjecture that the factors perceived as driving success by the entrepreneurs are explained by their major motivations to start an enterprise. By obtaining better training and investing in professional development, they can serve their clients better and help them improve their health and wellbeing. Moreover, the importance of the professional development indicators to the overall entrepreneurial success is in line with previous research on legitimacy and entrepreneurship. Selecting an adequate workforce composition can be particularly challenging for hybrid organizations as their employees have to respond to the demands of different institutional logics (e.g., business and social). Therefore, specialized training and development appears to be one of the major tools of "hybridizing" employees (Battilana et al. 2015). According to prior research on legitimacy, education and professional experience of the human capital significantly contribute to increased legitimacy, because it provides credibility (Tornikoski and Newbert 2007). In turn, the entrepreneurial perspective advocates that adequate human capital is linked with the survival and success of the enterprise (Combs et al. 2005). Considering that CAM enterprises aim at responding to consumer demands for more personalized services and "whole person" understanding (Winnick 2005), it seems that CAM micro-enterprises are mostly concerned with providing a good service. For instance, enterprises under conditions of legitimacy vacuum must establish a set of recognizable practices that are understood by the stakeholders and that will increase the enterprise ability to deal with its environmental deficiency (Dobrev and Gotsopoulos 2010). Therefore, given the hybrid nature of the CAM enterprise situated in a contested category due to its nonscientific boundaries (Mizrachi et al. 2005), human capital and the projection of a professional image seem to be perceived as crucial for success and survival.

Our respondents' emphasis on human capital by underlining training (qualifications of the human capital), professional development (adequate professional development and training), and organizational aspects (concerning the adequacy of the human capital to the organizational structure and needs) is in line with one of the 
five dimensions Battilana and Lee (2014) argue constitute hybrid organizing: workforce composition or whether human resources were socialized in the social or the commercial sector.

The next more important success indicators are management (financial, managerial, and ethical leadership of the organization) and marketing (e.g., market research, communication tools, promotion initiatives, and participation in events). These findings confirm Battilana and Lee's (2014) suggestion that "core organizational activities" (as, e.g., commercial and social activities) are a dimension of hybrid organizing together with "organizational culture," organizational shared values, and norms of behavior through leadership's meaning creation. One could argue that this dimension was captured by the management indicator present in our findings as it related to the skills of the managers, the ethical and moral conduct of the leaders, and their leadership capacity.

The indicators of management chosen by the entrepreneurs are composed by financial (e.g., growth) and nonfinancial measures (e.g., management and marketing skills, ethics, and leadership). Our findings show that the majority of the measures are operational (nonfinancial). The only financial measures appearing in the management indicator are profitability and annual turnover. These findings agree with Simpson et al. (2012) who argue that many enterprises run their business for other reasons (such as lifestyle, own satisfaction, customer orientation, service/product), rather than maximizing financial performance. However, financial measures (e.g., sales growth, ROE) are commonly used as the most important measure of success in entrepreneurship (e.g., a large amount of quantitative studies use financial measures as dependent variables) (Combs et al. 2005). Furthermore, financial measures of entrepreneurial success can increase legitimacy, because stakeholders use them to evaluate the enterprises' ability to sustain their business (Ashforth and Gibbs 1990). Other important factors are the skills and abilities of the managers (e.g., management and marketing skills, ethics, and leadership) to run the business (Tornikoski and Newbert 2007; Überbacher 2014). They are particularly relevant for a hybrid enterprise, because the managers' competences may be crucial in promoting and creating a favorable image of the enterprise and thus in mobilizing resources (Überbacher 2014). In support, most studies in entrepreneurship, and specifically micro-enterprises, demonstrate the role of the managers abilities in the success of the enterprise (Reijonen and Komppula 2007).

Next indicator, organizational aspects, concerns the adequacy of the human capital to the organizational structure and needs. This indicator seems to be related to organizational design (how leaders translate strategy into action including incentives, control systems, and organizational structure and governance), one of the five dimensions of hybrid organizing suggested by Battilana and Lee (2014). Further, these factors are positively associated with obtaining legitimacy and success of the enterprise (Tornikoski and Newbert 2007).

The least important indicators to the overall success of micro-enterprises are the infrastructure and external factors. It seems that the infrastructures, such as the conditions of the facilities and its surrounding, are perceived secondary to the business success in our sample of CAM micro-enterprises. This is in contrast with the 
entrepreneurship literature, which reports that infrastructures significantly impact success and the relative performance of the enterprise (Reijonen and Komppula 2007).

Finally, external factors are associated with the environmental context of the enterprise, such as political and economic factors, and regulation. The legitimacy literature argues that the external environment is instrumental for legitimacy gains and is thus critical to increase firms' survival chances (Tornikoski and Newbert 2007). The external environment of the enterprise may as a matter of fact facilitate or hinder the development of the enterprise (Dobrev and Gotsopoulos 2010). Further, research in entrepreneurship also suggests that external factors strongly influence the success of the enterprise (Short et al. 2009; Simpson et al. 2012). One would think that the external factors would be of particular importance to CAM's success, due to the enterprises' hybrid context restraining their overall success and legitimacy to operate. Our findings suggest the opposite. It appears that the CAM entrepreneurs rely on what they are able to manage and what is in their direct control. One explanation might be the strategic view on legitimacy, namely, that the enterprise can cultivate legitimacy through managerial actions, professionalism, and customer service (Short et al. 2009). Our findings are in line with Battilana and Lee's suggestion of interorganizational relationships as one of the five dimensions of hybrid organizing in the sense that they relate to networks of relationships with investors or partners, external factors which they can control.

\section{Implications for Theory and Practice}

We contribute to the literature in a number of ways. One of the most important contributions is the application of cognitive mapping with an MCDA method to construct a success framework from the point of view of entrepreneurs and in particular to hybrid enterprises.

The advantage of such a constructivist approach, as opposed to survey methods commonly used in prior research, is that it allows us to (1) identify objective and subjective components of success and the cause-and-effect linkages between criteria (that allowed the FPVs to be identified), which might otherwise go undetected by the use of statistical approaches alone; (2) calculate the trade-offs between these components contemplating the managers' practical experience and collective perceptions and taking account explicitly for the negotiated ranking of the different components of success while adding simplicity and transparency to the evaluation framework; (3) provide the panel members with the opportunity to reflect on the assessments projected and make suggestions for improvement; and (4) develop a process-oriented framework that, with proper adjustments, can be easily replicated with a different group of managers and/or within other contexts. The MCDA approach guides the decision-makers to discuss and learn about the situation in an open environment. This is important, because it leads to a justifiable and explainable course of action of the evaluation framework from the managers point of view 
(Ferreira et al. 2015). Thus, we can see that in our context - hybrid microenterprises - managers identify external factors as marginally important for the success of their enterprises. Although, this is a relevant to respond to Battilana and Lee's (2014) call for construction of hybrid performance measures, this is a finding which contrasts prior research about the importance of environmental conditions for the success of organizations (Short et al. 2009; Simpson et al. 2012). It is giving us food for thought for future research by raising the question whether limited resources prevent hybrid micro-entrepreneurs from having a clear sense of the path to longterm longevity of the enterprise so that they can achieve their economic or noneconomic goals.

On a broader scale, our study responds to recent calls for research on sustainable success of micro-enterprises (Short et al. 2009; Markman and Waldron 2014) and hybrid enterprises (Battilana and Lee 2014). Since hybrid organizations have dual identities, we explore the idea of founding motives being present in the notion of success of micro-entrepreneurs. Our findings demonstrate that noneconomic goals prevail both in the reasons of the founding of the enterprises and the notion of success. We develop a success framework directly with the managers of the enterprises. This is in contrast to prior empirical research that has resorted mainly to measures selected by researchers. Based on the results from the two samples in the study, we see a clear correspondence between the professional factor as an impetus to founding and professional development and training being seen as the key success factors by the entrepreneurs. We believe that the attempt to link motivations to perceptions of success is unique and contributes to the entrepreneurship literature. We further contribute to society by designing our study with an outreach component. The participants in the MCDA sessions were immersed in an interactive and iterative discussion about success factors, which helped them get a better understanding of the stance of their enterprises. The resulting evaluation framework was used to rank order their enterprises and to identify key areas for improvement. The entrepreneurs felt that the time invested in the exercise was worth it and it contributed to their professional development.

Micro-enterprises play a significant role in economic growth; however, because of their size and scale disadvantages, they are not able to sustain the same growth as bigger firms (Markman and Waldron 2014). Due to these constraints, microenterprises build their own competitive dynamic and logic, which influences the way they measure the enterprise success. Micro-enterprises in such market conditions focus on nonfinancial measures to assess success, unlike larger companies, where growth is particularly relevant to measure success. Further, the hybrid nature of the micro-enterprises adds a layer of interest as such enterprises evaluate success differently when compared to regular enterprises. It appears that human capital is of utmost importance for hybrid micro-enterprises both in terms of original reasons for founding and in visions of success. Thus, the overarching question we want to pose is about the causes of low success rates among micro-enterprises. We believe that our study opens the door to the idea that micro-enterprises tend to fail a lot because they have alternative visions of success that do not necessarily comply with expectations from their environment and economic realities. 
We present the entrepreneur's point of view of success factors in complementary and alternative medicine (CAM) - a contested category. Even though our findings are idiosyncratic, the results of the analysis indicate an applicable evaluation framework for measuring the success of hybrid enterprises struggling with legitimacy issues. We believe that the combined use of cognitive mapping with MCDA techniques is a proper approach for our study due to the complexity of the issue and the limited resources available to the decision-makers. Nevertheless, further investigation with a different set of panel of decision-makers and within other contexts would allow for building a more stylized and generalizable framework.

\section{References}

Amit, R., MacCrimmon, K. R., Zietsm, C., \& Oesch, J. M. (2001). Does money matter?: Wealth attainment as the motive for initiating growth-oriented technology ventures. Journal of Business Venturing, 16(2), 119-143.

Ashforth, B. E., \& Gibbs, B. W. (1990). The double-edge of organizational legitimation. Organization Science, 1(2), 177-194.

Bana e Costa, C. A., De Corte, J. M., \& Vansnick, J. C. (2012). MACBETH. International Journal of Information Technology \& Decision Making, 11(2), 359-387.

Battilana, J., \& Lee, M. (2014). Advancing research on hybrid organizing - insights from the study of social enterprises. The Academy of Management Annals, 8(1), 397-441.

Battilana, J., Sengul, M., Pache, A. C., \& Model, J. (2015). Harnessing productive tensions in hybrid organizations: The case of work integration social enterprises. Academy of Management Journal, 58(6), 1658-1685.

Belton, V., \& Stewart, T. J. (2002). Multiple criteria decision analysis: An integrated approach. New York: Springer Science \& Business Media.

Combs, J. G., Crook, T. R., \& Shook, C. L. (2005). The dimensionality of organizational performance and its implications for strategic management research. In D. J. Ketchen \& D. D. Bergh (Eds.), Research methodology in strategy and management (pp. 259-286). Oxford: Emerald Group Publishing Limited.

Cooper, A. C., Gimeno-Gascon, F. J., \& Woo, C. Y. (1994). Initial human and financial capital as predictors of new venture performance. Journal of Business Venturing, 9(5), 371-395.

Courrent, J. M., \& Gundolf, K. (2008). Proximity and micro-enterprise manager's ethics: A French empirical study of responsible business attitudes. Journal of Business Ethics, 88(4), 749-762.

Dobrev, S. D., \& Gotsopoulos, A. (2010). Legitimacy vacuum, structural imprinting and the first mover disadvantage. Academy of Management Journal, 53(5), 1153-1174.

Doherty, B., Haugh, H., \& Lyon, F. (2014). Social enterprises as hybrid organizations: A review and research agenda. International Journal of Management Reviews, 16, 417-436.

Ferreira, F. A. F., Santos, S., \& Rodrigues, P. (2010). Adding value to bank branch performance evaluation using cognitive maps and MCDA: A case study. Journal of the Operational Research Society, 62(7), 1320-1333.

Ferreira, F. A. F., Marques, C. S. E., Bento, P., Ferreira, J. J. M., \& Jalali, M. S. (2015). Operationalizing and measuring individual entrepreneurial orientation using cognitive mapping and MCDA techniques. Journal of Business Research, 68(12), 2691-2702.

Frass, M., Strassl, R. P., Friehs, H., Müllner, M., Kundi, M., \& Kaye, A. D. (2012). Use and acceptance of complementary and alternative medicine among the general population and medical personnel: A systematic review. The Ochsner Journal, 12(1), 45-56.

Hmieleski, K. M., \& Baron, R. A. (2009). Entrepreneurs' optimism and new venture performance: A social cognitive perspective. Academy of Management Journal, 52(3), 473-488. 
Jones, P., Simmons, G., Packham, G., Beynon-Davies, P., \& Pickernell, D. (2014). An exploration of the attitudes and strategic responses of sole-proprietor micro-enterprises in adopting information and communication technology. International Small Business Journal, 32(3), 285-306.

Markman, G. D., \& Waldron, T. L. (2014). Small entrants and large incumbents: A framework of micro entry. The Academy of Management Perspectives, 28(2), 179-197.

Mizrachi, N., Shuval, J. T., \& Gross, S. (2005). Boundary at work: Alternative medicine in biomedical settings. Sociology of Health \& Illness, 27(1), 20-43.

Moss, T. W., Short, J. C., Payne, G. T., \& Lumpkin, G. T. (2011). Dual identities in social ventures: An exploratory study. Entrepreneurship Theory and Practice, 35(4), 805-830.

Murphy, G. B., Trailer, J. W., \& Hill, R. C. (1996). Measuring performance in entrepreneurship. Journal of Business Research, 36(1), 15-23.

Rauch, A., Wiklund, J., Lumpkin, G. T., \& Frese, M. (2009). Entrepreneurial orientation and business performance: An assessment of past research and suggestions for the future. Entrepreneurship Theory and Practice, 33(3), 761-787.

Reijonen, H., \& Komppula, R. (2007). Perception of success and its effect on small firm performance. Journal of Small Business and Enterprise Development, 14(4), 689-701.

Ruebottom, T. (2013). The microstructures of rhetorical strategy in social entrepreneurship: Building legitimacy through heroes and villains. Journal of Business Venturing, 28(1), 98-116.

Ruef, M., \& Scott, W. R. (1998). A multidimensional model of organizational legitimacy: Hospital survival in changing institutional environments. Administrative Science Quarterly, 43(4), 877-904.

Santos, F. M., \& Eisenhardt, K. M. (2005). Organizational boundaries and theories of organization. Organization Science, 16(5), 491-508.

Short, J. C., McKelvie, A., Ketchen, D. J., \& Chandler, G. N. (2009). Firm and industry effects on firm performance: A generalization and extension for new ventures. Strategic Entrepreneurship Journal, 3(1), 47-65.

Simpson, M., Padmore, J., \& Newman, N. (2012). Towards a new model of success and performance in SMEs. International Journal of Entrepreneurial Behavior \& Research, 18(3), 264-285.

Tornikoski, E., \& Newbert, S. (2007). Exploring the determinants of organizational emergence: A legitimacy perspective. Journal of Business Venturing, 22(2), 311-335.

Überbacher, F. (2014). Legitimation of new ventures: A review and research programme. Journal of Management Studies, 51(4), 667-698.

van Werven, R., Bouwmeester, O., \& Cornelissen, J. P. (2015). The power of arguments: How entrepreneurs convince stakeholders of the legitimate distinctiveness of their ventures. Journal of Business Venturing, 30(4), 616-631.

Winnick, T. A. (2005). From quackery to "complementary" medicine: The American medical profession. Social Problems, 52(1), 38-61.

Zahra, S. A., Gedajlovic, E., Neubaum, D. O., \& Shulman, J. M. (2009). A typology of social entrepreneurs: Motives, search processes and ethical challenges. Journal of Business Venturing, 24(5), 519-532. 